\title{
Two Records of the Yellow-bellied Racer in Saskatchewan
}

by William J. Maher, University of Saskatchewan, Saskatoon, and

W. Harrey Beck, Saskatchewan Museum of Natural History, Regina

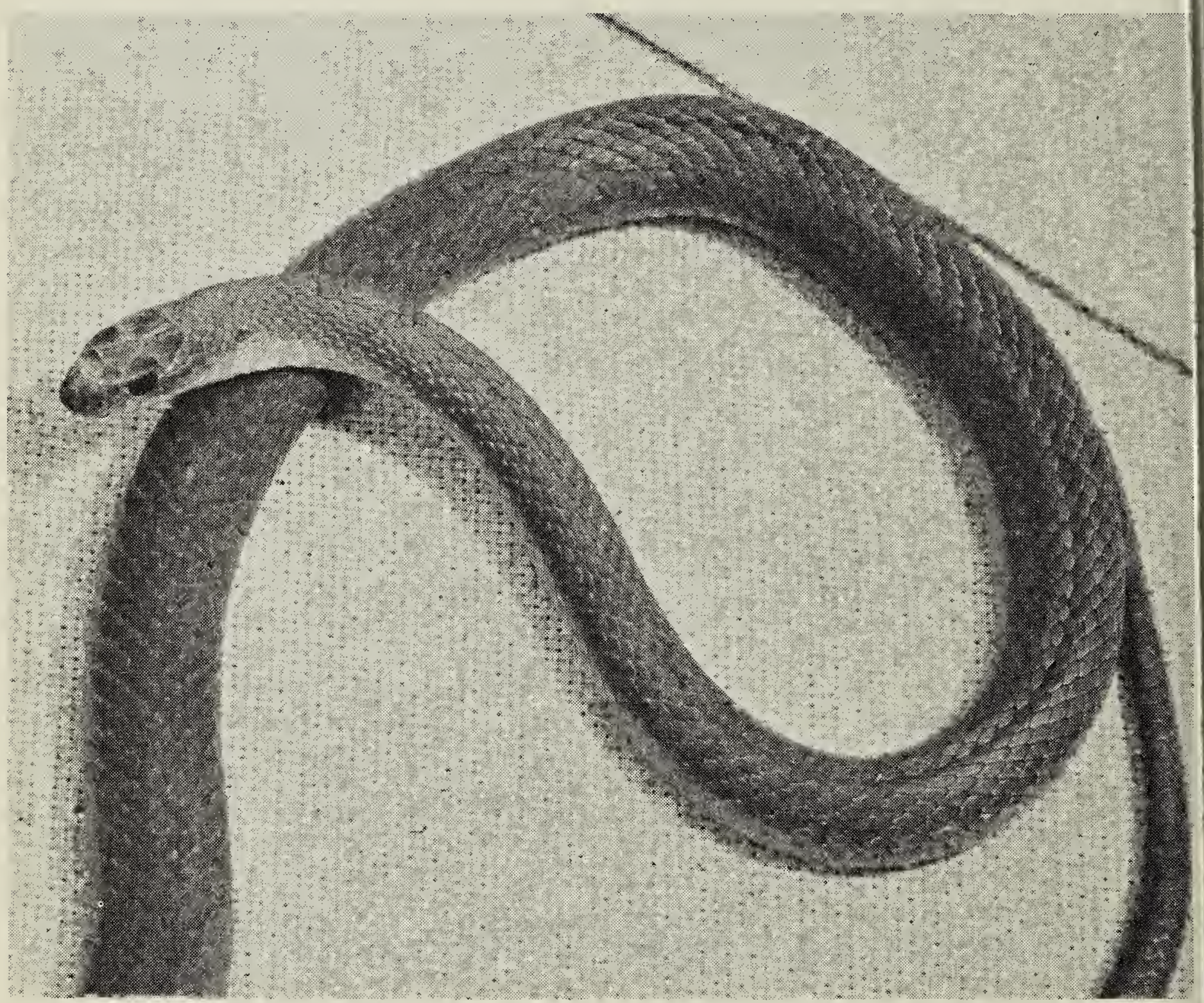

Photo by Norman Ferrier

A Yellow-bellied Racer (Coluber constrictor flaviventris) was collected, along with five Western Rattlesnakes (Crotalus viridis), on the Walt Larson ranch six miles east of Val Marie, Saskatchewan, on October 4,1964 . The snakes were collected by Mr. N. Lacoursiere of Ponteix who took them to the University of Saskatchewan Biology Museum in Saskatoon. Another racer collected on the same date at the same locality was submitted by Dr. G. R. Sherven to the Saskatchewan Museum of Natural History in Regina.

These are apparently the first records of the species for the Canadian prairies. The Yellow-bellied Racer occurs south of the Saskatchewan border in Montana and North Dakota and its presence in the Val Marie area, which has other southern affinities, is not surprising.

The specimen in Saskatoon is 107 $\mathrm{cm}$ (42 inches) long, and the one in Regina is $95 \mathrm{~cm}$ (37 inches) long. They are colored grayish-blue dorsally and yellow ventrally. These racers are identified by the color, smooth keelless scales, and the presence of 17 scale rows on the anterior part of the body. The anal plate and all caudal scutes are divided. 